\section{DESAFIOS EMERGENTES ACERCA DO EMPODERAMENTO DA MULHER ATRAVÉS DO ESPORTE}

\author{
EMERGING CHALLENGES FOR WOMEN'S EMPOWERMENT THROUGH \\ SPORT
}
DESAFIOS EMERGENTES ACERCA DEL EMPODERAMIENTO DE LA MUJER A TRAVÉS DEL DEPORTE

\section{Vera Lucia Brauner}

\section{Palavras-chave} Esportes.

Mulher.

Poder (psicologia).
Resumo: 0 empoderamento da mulher está na agenda internacional como desafio para o processo de mudança da atual situação social e econômica. Vários organismos internacionais vêm apontando a necessidade de políticas de fortalecimento da condição feminina, diante do quadro ainda hoje pouco favorecedor da participação das mulheres nos diferentes cenários. A partir dessas reflexões, o trabalho tem como objetivo apresentar alguns aspectos sobre a situação da mulher e esporte, apontando alguns desafios emergentes para as políticas de fortalecimento do esporte voltado a meninas e mulheres no Brasil.

\section{Keywords:}

Sports.

Woman.

Power (psychology).

Deportes.

Mujer.

Poder (psicología).
Abstract: Women' empowerment is on the international agenda as a challenge to the process of changing the current social and economic situation. Several international organizations have pointed out the need for policies that strengthen the status of women in a scenario that, even today, does little to favor women's participation in different settings. Based on these considerations, this study aims to present aspects on the situation of women in sports, pointing out some emerging challenges for policies to strengthen sports related to young girls and women in Brazil.

Resumen: El empoderamiento de la mujer se ubica en la agenda internacional como desafío para el proceso de cambio de la actual situación social y económica. Muchas organizaciones internacionales apuntan la necesidad de políticas de fortalecimiento de la condición femenina, en el marco de una participación todavía poco desarrollada en distintos escenarios. A partir de estas reflexiones, el trabajo tiene como objetivo presentar aspectos sobre la situación de la mujer y del deporte, señalando algunos desafíos emergentes para las políticas de fortalecimiento del deporte para niñas y mujeres en Brasil.
"Pontifícia Universidade Católica do Rio Grande do Sul, Porto Alegre, RS. E-mail: vera.brauner@pucrs.br

Recebido em: 26-06-2014 Aprovado em: 19-10-2014 (c) (1) (8) Licence 


\section{INTRODUÇÃO'}

Trago no texto três subtemas, fundamentalmente: primeiro proponho pensar sobre a mulher e os dados relativos ao contexto social e econômico, considerando as orientações internacionais sobre a necessidade de equiparação entre as condições de vida e trabalho entre homens e mulheres. Abordo também os aspectos relativos ao trabalho doméstico e violência contra a mulher. Compreender esse contexto justifica o segundo assunto quando escrevo sobre a necessidade de empoderamento da mulher, como possibilidade de alavancar o processo de mudança da atual situação social e econômica do Brasil enquanto país em desenvolvimento. Ao final, reflito sobre a condição da mulher e o esporte. A opção por esses três temas se dá pela necessidade de pensar a mulher e o esporte a partir de uma complexidade que atravessa a situação feminina e que acaba determinando a exclusão da mulher nos mais diferentes âmbitos. Este trabalho tem como objetivo apresentar algumas reflexões referentes ao tema mulher e esporte, especialmente no contexto brasileiro enquanto país em desenvolvimento.

\section{A CONDIÇÃO FEMININA: ALGUMAS REFLEXÕES INTRODUTÓRIAS}

Apesar dos avanços dos últimos anos em relação às garantias de não discriminação e tratamento igualitário entre homens e mulheres, as estatísticas atuais mostram que ainda há muito por fazer, e a promoção da igualdade de gênero está no cerne das políticas sociais e econômicas na maioria dos países.

Taxas de emprego dos homens mais altas que as das mulheres, que seguem predominando em determinados setores e profissões menos valorizadas e pior remuneradas, e a baixa participação de mulheres em cargos de direção e em espaços políticos e econômicos de decisão são, ainda hoje, desafios a enfrentar em nível internacional.

Na América Latina e Caribe, as preocupações são as mesmas. O Programa das Nações Unidas para o Desenvolvimento (PNUD), em seu Informe sobre Desenvolvimento Humano (TRABAJO..., 2013), fala sobre a importância da atenção à saúde, educação, proteção social, empoderamento legal, não discriminação e trato igualitário em relação à mulher como aspectos cada vez mais cruciais para alcançar a estabilidade social e política dos países.

Em um documento chamado Trabajo Decente e Igualdad de Género: políticas para mejorar el acceso y la calidad del empleo de las mujeres de America Latina y Caribe (TRABAJO..., 2013), a Organização Internacional do Trabalho (OIT), Comissão Econômica para América Latina e Caribe (CEPAL), Organização das Nações Unidas para a Alimentação e Agricultura (FAO), Programa das Nações Unidas para o Desenvolvimento (PNUD) e ONU Mulheres (entidade da ONU para a Igualdade de Gênero e Empoderamento das Mulheres) se reuniram para elaborar de forma conjunta um informe regional, dirigido a apoiar e colocar em ação políticas de emprego para a igualdade de gênero. $O$ documento define como condição para o crescimento econômico a urgência de políticas que visem o fortalecimento, inserção e permanência da mulher no trabalho, visando a superação de problemas estruturais dos países.

Em 2012, a empresa Ernst \& Young Terco entrou como apoiadora oficial dos Jogos Olímpicos Rio-2016, como fornecedora exclusiva de serviços de consultoria para o Comitê

1 Este trabalho é resultado do estágio para estudo e aperfeiçoamento do Observatório Olímpico do Esporte e Coesão Social (OECS), junto ao Centro de Estudos Olímpicos (CEO) da Universidade Autônoma de Barcelona (UAB) em 2014, tendo como apoiadora a Pontifícia Universidade Católica do Rio Grande do Sul e financiamento do Programa de Bolsas Ibero-Americanas do Santander Universidades. 
Organizador, por entender como decisivo nessa iniciativa o alinhamento dos valores do Movimento Olímpico com os da Ernst \& Young Terco. A empresa considera que, no mundo dos negócios, o desequilíbrio nas relações de gênero na economia mundial segue existindo. A empresa destaca, numa perspectiva econômica e de desenvolvimento sustentável, a importância da presença feminina em postos de alta administração nas empresas.

O documento intitulado Grandes empreendedoras: o poder das mulheres para estimular o crescimento econômico de Ernest \& Young Terco aponta que:

\begin{abstract}
Por exemplo, embora o número de CEOs mulheres que fazem parte da lista Fortune 500 tenha dobrado na última década, em 2012 elas representavam apenas $4 \%$ do total. Quando as economias industrializadas são vistas em grupo, apenas $11,1 \%$ dos membros dos conselhos de administração são mulheres, e, em mercados de rápido crescimento, essa representação cai para 7,2\%. Já no Brasil, pesquisa recente conduzida pelo Instituto Brasileiro de Governança Corporativa (IBGC) indica que as mulheres ocupam 7,7\% das posições na alta administração das companhias brasileiras abertas.
\end{abstract}

Também no Plano Nacional de Políticas para as Mulheres estão colocados, entre outros objetivos (BRASIL..., 2013, p. 14-15):

Ampliar a participação e a permanência das mulheres no mundo do trabalho, garantindo a qualidade nas condições e igualdade de rendimentos.

Promover a organização produtiva e o acesso à renda para mulheres, especialmente das em situação de vulnerabilidade social.

$[\ldots]$

Promover políticas que visem o compartilhamento das responsabilidades domésticas e que contribuam para a superação da divisão sexual do trabalho.

Em relação à pobreza, cabe ressaltar alguns dados que se referem à condição de mulheres, meninas e trabalho doméstico.

$\mathrm{Na}$ América Latina, a pobreza diminuiu a partir da década de 2000. Atualmente, pouco mais de um terço da população da região é pobre e $13 \%$ são indigentes. No entanto, as famílias pobres chefiadas por mulheres mostram uma tendência inversa, porque enquanto a pobreza global diminui na região, as famílias pobres chefiadas por mulheres aumentam. É uma mulher que dirige $43 \%$ das famílias indigentes e $38 \%$ das famílias pobres na América Latina.

O trabalho doméstico infantil é outra preocupação que cabe aqui destacar. Na América Latina e Caribe, os dados da OIT apontam que, mesmo sendo difícil determinar quantos meninos e meninas menores de 18 anos estão submetidos ao trabalho infantil doméstico, o número estimado seja de dois milhões e, destes, quase $90 \%$ são meninas (ORGANIZACIÓN..., 2011).

Em 12 de junho de 2013, no Dia Contra o Trabalho Infantil, o Fundo das Nações Unidas para a Infância (UNICEF) publicou um comunicado global alertando para 0 fato de que existem milhões de crianças no mundo envolvidas em alguma forma de trabalho que gera perigo ou exploração, além de prejuízos em relação à saúde, à educação, ao bem-estar e ao desenvolvimento geral. De acordo com as últimas estimativas da OIT, 7,4 milhões de crianças se envolvem com trabalho doméstico, que é desproporcionalmente realizado por meninas. 
Segundo o Fundo, os trabalhadores domésticos estão entre os trabalhadores mais explorados e abusados, por uma série de razões (FONDO..., 2014).

No Brasil, temos a situação das meninas cuidadoras de seus irmãos. Como a frequência à escola brasileira, em geral, ocorre em um turno, supõe-se que, no turno inverso, as meninas, mais do que os meninos, fiquem em casa, ocupando-se dos trabalhos domésticos e/ou do cuidado dos irmãos menores. A permanência das meninas no ambiente doméstico pelas imposições culturais que outorgam, ainda hoje, que as mulheres/meninas se responsabilizem pelo cuidado da casa e dos filhos/ irmãos, faz com que elas tenham menos oportunidades de praticar esportes e estejam mais expostas a todo tipo de violência doméstica.

No Brasil, a Lei n-11.340/2006, conhecida por Lei Maria da Penha (BRASIL..., 2006), vem contribuindo muito no sentido de coibir a violência doméstica e familiar contra a mulher. Entretanto, ainda é necessária a criação de estratégias para possibilitar e estimular as denúncias em relação aos diferentes tipos de violência sofrida pelas meninas e mulheres no Brasil e em muitos outros países, em função das dificuldades que se interpõem por diferentes motivos, como medo e ameaças, o que complica enormemente a confiabilidade dos dados.

O documento Empoderamento das mulheres: avaliação das disparidades globais de gênero, do Fórum Econômico Mundial e Fundo de Desenvolvimento das Nações Unidas para a Mulher (FUNDO..., 2005), relata sobre 0 aspecto menos avaliado em estatísticas precisas: a violência contra a mulher. Isto se explica pela complexidade das questões sociais e culturais que, ao combinar-se com o estigma e o temor da denúncia, contribui para que um pequeno índice de casos seja registrado em relação à violência doméstica e ao abuso sexual de meninas e meninos.

Azevedo (2014) informa que, no Brasil, considerando a população de zero a 19 anos, os casos de violência sexual atingem $20,9 \%$ dos meninos e $75,5 \%$ das meninas. A violência, em geral, acaba por desenvolver menor capacidade de resiliência ${ }^{3}$ e uma baixíssima autoestima, tornando as crianças e jovens mais frágeis diante das exigências da vida como futuros adultos.

O aumento de capacidades individuais, do empoderamento da mulher e as relações de gênero igualitárias são tão importantes para o desenvolvimento da estabilidade e bem-estar social quanto para o desenvolvimento econômico, como colocado no Informe sobre Desarrollo Humano. (2013).

Podemos ver então que o problema da desigualdade de gênero segue sendo objeto de preocupação e discussão e que as meninas e mulheres continuam tendo um papel subalterno no tecido social e familiar. Neste sentido, os diferentes organismos internacionais apontam a necessidade de olhar para as meninas e mulheres não somente do ponto de vista de desenvolvimento sustentável, como também em relação aos direitos humanos. Assim, o empoderamento da mulher é fundamental para o avanço das sociedades em todos os aspectos.

\section{O EMPODERAMENTO FEMININO: AINDA FALTA MUITO...}

Atualmente, organizações internacionais e acordos entreos países recomendam a necessidade de ampliar a presença das mulheres nos espaços de poder e de decisão, bem como programar ações que favoreçam a participação das mulheres em todos os setores, como, por exemplo, a Convenção para Eliminação de Todas as Formas de Discriminações Contra a Mulher (CEDAW), as Conferências Internacionais do Cairo, Beijing, Durban, entre outras. 
A condição brasileira mostra o problema ainda existente. As mulheres brasileiras representam $52 \%$ da população, mas o Brasil encontra-se na $118^{\text {a }}$ posição no ranking da participação política das mulheres entre 198 países que foram objeto de análise do relatório Global Data Base of Quotas for Women (BRASIL..., 2013). O Plano Nacional de Políticas para as Mulheres, por exemplo, traz entre seus objetivos a meta de fomentar e fortalecer a participação igualitária e plural das mulheres nos espaços de poder e decisão.

O termo empoderamento e, em inglês, a expressão empowerment significam dar poder a, permitir ou também autorizar. Para um esclarecimento conceitual, sigo o sentido freiriano do empoderamento ${ }^{4}$, que pode estar associado à ideia da libertação do sujeito oprimido e a noção de conquista da liberdade (FREIRE, 2011). O sentido da expressão na língua inglesa remete a uma situação de passividade por parte do empoderado, já que, por definição, o poder lhe é dado por alguém. Neste sentido, Paulo Freire também ensina que o empoderamento, enquanto liberdade, não é um presente e nem está naturalmente posto. Adquire-se pela conquista e deve ser buscado constantemente. É neste sentido que devemos pensar o empoderamento das meninas e mulheres como conquista autogestionada.

Falar então de empoderamento feminino é dizer sobre a construção democrática nas tomadas de decisão, nas responsabilidades coletivas, que desafiam relações patriarcais e androgênicas, cristalizadas nas diferentes culturas e sociedades, que mantêm os privilégios de dominação dos homens sobre as mulheres e que vai gerar processos individuais e coletivos de apropriação de direitos sobre a vida da mulher em todos os âmbitos.

Ainda que, nos dias atuais, cada vez mais se fale sobre as questões de empoderamento das mulheres e a conscientização esteja melhorando, até o ano de 2005 não havia nenhum país que tivesse conseguido êxito no aspecto de gênero e mulheres (FUNDO..., 2005).

A ONU, em 2000, fez uma análise de quais eram os maiores problemas no mundo. A partir da análise, estabeleceu oito objetivos para o milênio, denominados Oito Jeitos de Mudar o Mundo, que deveriam ser atingidos até 0 ano de 2015. 0 terceiro dos oito objetivos diz respeito à necessidade de igualdade entre sexos e a valorização da mulher. 0 documento da Organização das Nações Unidas (2014) aponta dados sobre a condição feminina no Brasil:

\begin{abstract}
As mulheres já estudam mais que os homens, mas ainda têm menos chances de emprego, recebem menos do que homens trabalhando nas mesmas funções e ocupam os piores postos. Em 1998, 52,8\% das brasileiras eram consideradas economicamente ativas, comparadas a $82 \%$ dos homens. Em 2008, essas proporções eram de $57,6 \%$ e 80,5\%. A participação nas esferas de decisão ainda é pequena. Em 2010, elas ficaram com 13,6\% dos assentos no Senado, 8,7\% na Câmara dos Deputados e $11,6 \%$ no total das Assembleias Legislativas. ${ }^{5}$
\end{abstract}

Em 2011, a ONU lança o Relatório dos Objetivos de Desenvolvimento do Milênio 2011, no qual informa que muitos avanços foram feitos em uma década, como, por exemplo - no caso das mulheres -, a redução da mortalidade materna e a expansão de oportunidades para mulheres. No entanto, o documento mostra também que ainda há fragilidades importantes quando destaca "[...] que ainda temos um longo caminho a percorrer no empoderamento de mulheres e garotas". Destaca ainda que as conquistas dos Objetivos do Milênio passam

4 Paulo Freire coloca o empoderamento como categoria em seus escritos, mas faço aqui uma relação com as políticas de libertação/opressão, contidas em toda sua obra.

5 Disponível em: <http://www.objetivosdomilenio.org.br/mulher/>. Acesso em 20 jan. 2014. 
pela dependência da garantia do empoderamento das mulheres e oportunidades iguais entre gêneros. Este tema também está presente na página da ONU-Mujeres, ${ }^{6}$ entidade das Nações Unidas.

O empoderamento da mulher é, portanto, chave para a diminuição dos processos de exclusão social e constituição da autonomia, autoconfiança, participação política, desenvolvimento de liderança.

Podemos pensar, então, que o empoderamento implica em uma alteração significativa dos processos e das estruturas políticas, sociais, culturais e econômicas que reproduzem a posição da mulher como submissa e que, portanto, a constituição de ações de inclusão de mulheres e meninas em programas de fortalecimento da condição feminina pode representar um aspecto potencializador do empoderamento. Neste sentido é que entendemos crucial o papel de projetos esportivos para meninas, por todas as habilidades e valores aportados pelo esporte.

\section{ESPORTE E MULHERES: DAS (IN)VISIBILIDADES}

A importância da educação e do esporte para consolidação do exercício de direitos e construção da autonomia individual e coletiva, bem como para o desenvolvimento econômico e social, é reconhecida mundialmente.

Tal constatação está colocada nos Objetivos de Desenvolvimento do Milênio das Nações Unidas, que têm como uma de suas metas a eliminação das disparidades entre os sexos em todos os níveis de ensino até 2015.

A primeira Conferência Internacional sobre Mulher e Esporte ocorreu em Brighton, no Reino Unido, em 1994. Naquele momento foram discutidas questões sobre como acelerar 0 processo de mudança nos desequilíbrios existentes na participação da mulher e de meninas no esporte. Dessa conferência saiu um documento chamado Declaração de Brighton sobre mulher e esporte, que propõe princípios que devem orientar ações para incrementar a participação feminina. 0 documento apresenta dez princípios, dentre o quais destaco: a) equidade e igualdade na sociedade e no esporte - propondo que os estados e governos façam todo 0 esforço necessário para assegurar que instituições e organizações esportivas respeitem as disposições da Carta das Nações Unidas, da Declaração Universal dos Direitos Humanos, e da Convenção das Nações Unidas sobre a Eliminação de Todas as Formas de Discriminação contra as Mulheres; b) informação e investigação sobre esporte - sugere o desenvolvimento de políticas e programas para melhorar as informações e o conhecimento sobre o tema. Esse documento completa, em 2014, vinte anos, sendo que pouco se avançou no cumprimento dos princípios estabelecidos na declaração, em especial no Brasil.

Também na década de 1990, o Conselho Executivo da UNICEF elegeu a menina como foco de atenção. Na trajetória dessa ofensiva, cinco conferências internacionais foram realizadas pela ONU, nos anos 1990, sobre mulheres, desenvolvimento e educação. Particularmente a Conferência Mundial Educação para Todos em Dakar, em 2000, retomou os princípios da Conferência de Jomtien na Tailândia, que havia reiterado o enfoque da igualdade de acesso educacional entre os sexos e dedicou atenção especial à educação das meninas e

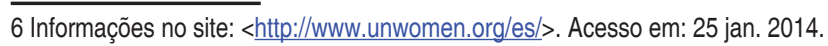


os problemas existentes sobre as diferenças entre os gêneros.

O Plano Nacional de Políticas para as Mulheres, lançado em 2013, trata a educação como um dos eixos fundamentais para a construção de uma sociedade igualitária entre mulheres e homens. Apesar disto, neste momento, quando está proposto o Plano Nacional de Políticas para Mulheres, previsto para 2013-2015, a educação e o esporte no Brasil ainda não contemplam adequadamente o princípio da igualdade de gênero. $O$ documento aponta que algumas ações e programas são hoje executados, mas é necessário acelerar o fortalecimento dessas ações, no âmbito da educação e do esporte, em busca de uma condição mais igualitária para meninas e jovens (BRASIL..., 2013).

A UNICEF tem como um dos seus princípios norteadores o esporte como direito, que também está garantido no Brasil pelo art. 31 da Convenção sobre os Direitos da Criança e pelo Estatuto da Criança e do Adolescente (ECA). A inclusão como princípio, visando especialmente os mais excluídos, busca garantir aos jovens e crianças a participação sem discriminação de idade, etnia e gênero. A preocupação com as diferentes formas de violência também está colocada como um dos princípios enquanto possibilidade de garantia de segurança e proteção através do esporte.

Muitos dos valores fundamentais inerentes ao esporte são também compatíveis com os princípios necessários para 0 desenvolvimento de habilidades para a vida, como 0 empoderamento dos indivíduos, aumento do bem-estar psicossocial, autoestima e melhoria na qualidade dos relacionamentos com outras pessoas.

No documento da Organização das Nações Unidas (2003, p. 16) Esporte para o Desenvolvimento e a Paz, são destacadas 21 habilidades e valores alcançados através do esporte. No mesmo documento, um dos tópicos dirige-se especialmente ao tema do esporte para a educação e inclusão de meninas, destacando que as "[...] habilidades e os valores aprendidos com o esporte são especialmente importantes para as meninas, uma vez que elas têm menos oportunidades de interação social do que os meninos fora de casa". 0 documento traz ainda que:

Através do esporte, as meninas têm a chance de serem líderes e de melhorar sua autoconfiança e autoestima. Quando as meninas começam a praticar esportes, também adquirem novas relações interpessoais e acesso a novas oportunidades, permitindo que se tornem mais envolvidas na escola e na vida da comunidade (ORGANIZAÇÃO DAS NAÇÕES UNIDAS, 2003, p. 17).

O grupo financeiro Massmutual Financial Group and Oppenheimer Founds publicou um documento intitulado Do vestiário ao Conselho de Administração: uma pesquisa sobre esportes na vida de mulheres executivas. Nesse documento, informam que $81 \%$ das mulheres executivas praticaram esportes e que $69 \%$ delas colocam o esporte como potencializador de suas habilidades de liderança para o sucesso profissional. ${ }^{7}$

Também no documento da Assembléia Parlamentar do Conselho da Europa Discriminação contra mulheres e meninas nos esportes está posto que, apesar do esporte ser um fator revigorante na sociedade, em muitos países, mulheres e meninas não têm acesso a atividades esportivas, nem desempenham um papel significativo nas entidades dirigentes do setor. $^{8}$

7 ERNEST \& YOUNG TERCO. Grandes empreendedoras: o poder das mulheres para estimular o crescimento econômico. São Paulo, 2012. 
Em 2007 a publicação da ONU Mulheres, igualdade de gênero e os esportesapontou a importância do esporte como possibilidade de desafiar os estereótipos e discriminação de gênero constituindo-se em um potente promotor da igualdade, autonomia e empoderamento feminino. Em particular, mulheres em posição de liderança nos esportes podem dar forma às opiniões sobre a capacidade das mulheres como líderes e tomadoras de decisões, especialmente em setores tradicionalmente dominados por homens (ORGANIZAÇÃO,.... 2007). Três anos mais tarde, em 2010, foi criado o ONU Mulheres, com objetivo de unir esforços internacionais para promoção da igualdade de gênero e empoderamento das mulheres. Essa entidade participou da 5 a Conferência Mundial do COI sobre as mulheres e o esporte, no ano de 2012, pela primeira vez.

A gestão do esporte também demonstra que os cargos diretivos seguem sendo um espaço fundamentalmente masculino. O Comitê Olímpico Internacional publicou dados referentes à participação da mulher em cargos e gestão do esporte. Nos órgãos executivos dos Comitês Olímpicos Nacionais existentes no mundo, elas ocupam 20,5\% do efetivo e nas federações internacionais esse número é de $17,6 \%$. No próprio $\mathrm{COI},{ }^{9}$ a representação feminina fica em torno de $19 \%$. Houve significativo progresso nos últimos anos, em relação à participação da mulher no esporte de alto rendimento, através da iniciativa do COI de introduzir cotas para a representação das mulheres nas organizações esportivas, entretanto, apesar do significativo avanço da presença feminina nos Jogos Olímpicos de Londres em 2012, participação feminina de 45\%, que representa um legado social, cultural e econômico -, ainda segue existindo um percentual muito baixo de mulheres nos diferentes comitês olímpicos, em especial nas representações de dirigentes e técnicas esportivas e também nas delegações olímpicas (OLIVERA, 2012). O autor destaca que, sem dúvida, a grande contribuição à história dos jogos e ao mundo em geral foi efetivamente a expressiva participação de mulheres esportistas nas 204 delegações participantes, mas ressalta que, como objetivo ainda por alcançar, está o incremento da prática esportiva com alcance especial às mulheres. As ações e políticas públicas e privadas de inserção de meninas e jovens no esporte podem potencializar o aumento da presença da mulher nos cargos de representação não somente do esporte, mas na gestão pública e privada.

Também são insuficientes ainda hoje os dados estatísticos sobre mulher e esporte. Crespo (2007) comenta que cada vez mais aumenta a oferta de esportes e atividades físicas em países desenvolvidos, mas que os estudos sobre atividades físicas para meninas são escassos ou os que são realizados nos mostram que a realidade e as estatísticas indicam que estamos longe da transformação do esporte, que ainda se mantém herarquizante e generificado.

Neste sentido, é necessário ampliar o fomento de estudos sobre esporte, inclusão e mulheres que abranjam pesquisas focadas na participação de meninas desde a infância, como forma de aumentar o número de pesquisas que analisem a realidade brasileira, considerando que a incorporação e consolidação de hábitos esportivos que ajudem no processo formativo em geral, na melhora da autoestima e no necessário empoderamento da mulher deve iniciar em idades mais precoces. Ou seja, necessitamos ter informação qualitativa e quantitativa atualizada sobre a participação de meninas no esporte.

Destaco um aspecto no Plano Nacional de Política para as Mulheres, no capítulo 8, onde encontramos referência ao esporte e ao lazer como fatores essenciais à promoção da qualidade de vida, da inclusão social, da cidadania e do desenvolvimento humano. $O$ documento

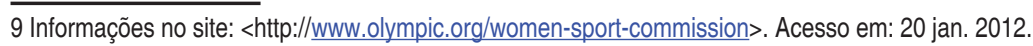


refere as possibilidades de participação das mulheres em atividades esportivas e de lazer, trazendo considerações sobre os problemas ainda enfrentados pelas mulheres, ponderando os aspectos culturais de divisão dos espaços públicos para homens e privado/doméstico para as mulheres. 0 documento propõe promover a inserção igualitária de mulheres e homens na área do esporte, seja ele profissional, não profissional, e traz, entre outros objetivos: valorizar e promover a participação das mulheres no esporte e no lazer, favorecendo maior divulgação; estimular, ampliar e qualificar 0 acesso de meninas, adolescentes, mulheres adultas e idosas ao esporte e ao lazer, promovendo a qualidade de vida, a inclusão social, a cidadania e 0 desenvolvimento humano. $O$ Plano ainda prevê, como uma de suas linhas de ação, o estímulo às práticas esportivas pelas mulheres e a ampliação de sua participação nos programas e projetos públicos voltados para o esporte e o lazer, articulando a incorporação da perspectiva de gênero nas políticas públicas e as dimensões raciais, étnicas, de origem, de classe social, de idade, de orientação sexual, de identidade de gênero e de mulheres com deficiência.

O Observatório Brasil da Igualdade de Gênero ${ }^{10}$ considera, na sua atuação, um conjunto de áreas temáticas onde o esporte está colocado como uma das dimensões para a promoção da qualidade de vida, da inclusão social, da cidadania e do desenvolvimento humano. Encontramos na página do Observatório um texto informativo onde está destacada a indispensável atuação do Estado para o fortalecimento das políticas públicas que garantam às mulheres o pleno direito ao esporte e lazer.

Por outro lado, soa um tanto estranho que, no Brasil, a preocupação com a inserção da mulher no esporte conste explicitamente no Plano Nacional de Política para as Mulheres e no Observatório Brasil da Igualdade de Gênero e não esteja presente na Política Nacional de Esporte. Ao acessar o documento da Política Nacional de Esporte, buscando através do localizador as palavras gênero e mulher, nada foi encontrado. No Plano Nacional de Política para as Mulheres, onde é tratada a questão do esporte, ao buscar pela palavra esporte, ela aparece 37 vezes.

Também chama a atenção o texto do documento encaminhado com propostas tiradas na plenária final da III Conferência Nacional do Esporte, realizada em 2010 no Brasil. 0 texto não apresenta nada referente ao tema mulher e esporte em nenhuma das linhas temáticas definidas. É possível encontrar temas genéricos que fazem referência a aspectos como: atenção à reversão do quadro atual de injustiças; exclusão e vulnerabilidade social; esporte e lazer como direitos de cada um e dever do Estado; universalização e inclusão social; democratização da gestão e da participação; e respeito à diversidade. Supostamente, devem estar inscritas aí as preocupações com gênero e esporte, mas não estão explícitas.

Ao visitar a página do Ministério do Esporte do governo brasileiro, responsável por construir uma Política Nacional de Esporte, não encontrei nada referente ao tema mulher e esporte. Há apenas um link dentro dos programas e ações do ministério que trata de um grupo de trabalho para discutir soluções e buscar melhorias para o futebol feminino. Também na página da Secretaria Nacional de Esporte Educação, Lazer e Inclusão Social, dentro do Ministério do Esporte, estão listados como missão da secretaria dez itens, e nenhum deles menciona qualquer coisa sobre inclusão e mulheres no esporte ou faz qualquer referência em relação ao tema. A Rede CEDES, da mesma secretaria, tem um Repositório Institucional onde disponibiliza arquivos digitais referentes à produção científica decorrente de pesquisas realizadas pela Rede CEDES. Na busca avançada, usando as palavras gênero e esporte, aparecem apenas cinco documentos. 
Assim, conhecer os programas e projetos, compartilhar experiências e investir em pesquisas é uma das possibilidades de descortinar e avançar na situação atual.

\section{CONSIDERAÇÕES FINAIS E RECOMENDAÇÕES}

Se, historicamente, faz 31 anos que o $\mathrm{COI}$ incorporou as mulheres como membros do organismo, e há 17 anos se aplicam plenamente os programas e processos para ajudar as mulheres a aceder de forma sistemática aos níveis mais altos da administração esportiva e à competição, podemos perceber que os avanços existiram, e que os últimos 17 anos foram cruciais para a inserção de mulheres no esporte, mas ainda há muito por fazer.

A formação humana passa pelo incremento da autoestima, condição prévia e necessária para o empoderamento e liderança, e, neste sentido, o esporte pode representar uma ferramenta eficiente e básica para a realização pessoal e a autoconfiança da mulher. O potencial do esporte como um recurso para o desenvolvimento e a paz ainda precisa ser plenamente apreendido e deve se constituir como pauta urgente nas políticas públicas e privadas.

Os benefícios sociais dos esportes - em especial do esporte com foco na inclusão social, projetos sociais e outras manifestações que visem a formação humana - devem ser impulsionados em prol do desenvolvimento sustentável, da paz e dos direitos humanos, e logicamente em prol da igualdade de gênero e do empoderamento das mulheres. A ampliação de modelos de mulheres empreendedoras, com capacidade de liderança, com participação efetiva em todos os âmbitos da sociedade, pode ser conseguida através da união de esforços para a promoção e aumento da participação feminina no esporte.

Para a potencialização de aspectos econômicos e de desenvolvimento sustentável, torna-se emergente a implementação crescente de projetos esportivos para meninas e jovens, especialmente aquelas em situação de exclusão social. As informações apresentadas neste trabalho indicam a preocupação de organismos internacionais com a maior participação da mulher no esporte para ampliar também o desenvolvimento econômico mundial. O Brasil, entretanto, carece ainda de políticas de inclusão da mulher no esporte e de dados significativos para melhor compreensão da situação da menina/mulher esportista.

Também preocupam os dados de violência contra a mulher e as dificuldades existentes ainda hoje de se ter mais informação sistematizada sobre o que acontece com mulheres e meninas no ambiente doméstico. Pensar a violência contra a mulher em relação ao tema do esporte diz respeito à necessidade de empoderamento da mulher também nas questões de enfrentamento das desigualdades e da violência.

As carências de estudos qualitativos e quantitativos sobre a inserção de meninas através do esporte exigem mais investimentos. Não somente para gerar mais informações e pesquisas sobre participação de meninas e jovens no esporte, mas, também, porque com as informações levantadas torna-se possível orquestrar mais projetos esportivos para as meninas. O processo é lento, mas necessário para mudar a realidade atual no que diz respeito ao tema.

A ampliação no oferecimento de programas sociais esportivos para meninas no Brasil deve ser discutida, e mais estatísticas sobre a participação de meninas no esporte devem ser produzidas, buscando a construção de um legado social positivo para os megaeventos que virão e especialmente para a construção de um processo civilizatório mais justo e humano. 
O trabalho realizado gerou inquietações sobre a situação da mulher e esporte. Coloco a seguir algumas recomendações:

- apoiar projetos de pesquisa voltados à inserção da menina no esporte, de forma a ampliar 0 acervo de consulta existente neste momento;

- gerar mais informações e levantamento de dados da realidade do esporte, em especial da participação feminina, para responder às necessidades do sistema esportivo brasileiro;

- dar visibilidade à questão de gênero e esporte nas políticas públicas brasileiras nos níveis federal, estadual e municipal;

- garantir o apoio político e financeiro a projetos e intervenções relacionados ao tema menina-esporte;

- pensar a criação de um centro de documentação que aporte dados quantitativos e qualitativos sobre o esporte educacional, recreativo e de rendimento em âmbito nacional, estadual e municipal que reúna todas as informações relativas à participação de meninas no esporte, bem como outros dados, permitindo o monitoramento e facilitação de acesso às informações;

- a partir do centro de documentação, o banco de dados se retroalimentaria com novas publicações e pesquisas realizadas com apoio financeiro de entidades públicas e privadas;

- incluir o tema mulher e esporte quando das capacitações de agentes sociais, técnicos e profissionais da área da Educação Física em relação aos problemas de gênero relacionados às meninas e suas consequências na vida adulta;

- atender às orientações dos documentos oficiais de organismos nacionais e internacionais sobre a necessidade de constituição de políticas de inserção da mulher no esporte.

Ainda são muitos os desafios a enfrentar e inúmeros os nós na direção de um país que entenda a contribuição do esporte como possibilidade de mudança na realidade social e econômica. Neste momento, ainda é necessário avançar em determinados aspectos e, para tanto, há necessidade de que alguns compromissos sejam assumidos a partir de uma agenda emergente.

\section{REFERÊNCIAS}

AZEVEDO Maria Amélia. Um cenário em (des)construção. Disponível em: <http://www.unicef. org/brazil/pt/Cap 01.pdf>. Acesso em: 3 fev. 2014.

BRASIL. Lei no 11.340/2006, de 7 de agosto de 2006. Lei Maria da Penha. Disponível em:< http://www.planalto.gov.br/ccivil 03/ ato2004-2006/2006/lei//11340.htm >. Acesso em: 20 fev.2014.

BRASIL. Ministério do Esporte. Política nacional de esporte. Brasília, 2005. Disponível em: $<$ <http://www.esporte.gov.br/index.php/meioacademico/83-ministerio-do-esporte/institucional/oministerio/sala-de-imprensa2/21849-politica-nacional-do-esporte. Acesso em: 01· fev. 2014. 
BRASIL. Presidência da República. Secretaria de Políticas para as Mulheres. Plano nacional de políticas para as mulheres. Brasília, 2013.

CRESPO, Clara López. Gènere i activitat física: interessos, pràctiques esportives i imatge corporal en l'adolescència. Quadern Dones i Esport, Barcelona, p. 27-38, 2007.

FONDO DE LAS NACIONES UNIDAS PARA LA INFANCIA. El estado mundial de la infancia de 2014 en cifras: todos los niños y niñas cuentan. Revelando las disparidades para impulsar los derechos de la niñez. Disponível em: <http://www.unicef.org/spanish/sowc2014/numbers/>. Acesso em: 10 fev. 2014.

FREIRE, Paulo. Pedagogia do oprimido. 50. ed. Rio de Janeiro: Paz e Terra, 2011.

FUNDO DE DESENVOLVIMENTO DAS NAÇÕES UNIDAS PARA A MULHER.

Empoderamento das mulheres: avaliação das disparidades globais de gênero. Genebra, 2005.

OLIVERA, Javier. Apuntes para el siglo XXI. APUNTS Educación Física y Deportes, Barcelona, n. 109, p. 7-10, jul./sept. 2012.

ORGANIZAÇÃO DAS NAÇÕES UNIDAS. Esporte para o desenvolvimento e a paz: em direção à realização das metas de desenvolvimento do milênio. Nova lorque, 2003.

ORGANIZAÇÃO DAS NAÇÕES UNIDAS. Mulheres, igualdade de gênero e os esportes. Nova lorque, 2007.

ORGANIZAÇÃO DAS NAÇÕES UNIDAS. Objetivos do milênio, 2000. Disponível em: <www. objetivosdomilenio.org.brl>. Acesso em: 18 jan. [2014].

ORGANIZACIÓN INTERNACIONAL DEL TRABAJO. La igualdad en el trabajo: un objetivo que sigue pendiente de cumplirse: informe del Director General. Ginebra, 2011.

PROGRAMA DE LAS NACIONES UNIDAS PARA EL DESARROLLO. El ascenso del sur: progreso humano en un mundo diverso. Nueva York, 2013.

TRABAJO decente e igualdad de género: políticas para mejorar el acceso y la calidad del empleo de las mujeres en America Latina y el Caribe. Santiago de Chile: CEPAL, 2013. 